\title{
Suicídio de idosos e mídia: o que dizem as notícias?
}

\author{
Beltrina Côrte ${ }^{\mathrm{a} \text { * }}$ Hilma Tereza Tôrres Khoury ${ }^{\mathrm{b}}$, Luciana Helena Mussi a \\ a Pontifícia Universidade Católica de São Paulo (PUC-SP), São Paulo, SP, Brasil \\ ${ }^{b}$ Faculdade de Psicologia, Universidade Federal do Pará, Belém, PA, Brasil
}

Resumo: Como a mídia aborda o suicídio de idosos? E o que as notícias sobre suicídio de idosos nos dizem? Estas foram as perguntas que guiaram esta reflexão, que se debruçou sobre matérias de suicídios de idosos publicadas na mídia nacional, entre abril de 2010 e abril de 2013. Observamos que a palavra "suicídio", até pouco tempo atrás "aquela-que-não-deveria-ser-nomeada" na imprensa, aparece na maior parte das notícias, no título e nos textos, demonstrando que o suicídio, como problema de saúde pública, afasta-se do campo privado para ocupar e compor o espaço público. Constatamos que entre as principais situações de risco que levam os idosos a cometer um "gesto de comunicação" extremo estão os efeitos de uma política econômica recessiva e o prolongamento da vida sem dignidade, mediante o medo da dependência e do provável "trabalho" aos demais; situações que indicam serem essenciais o desenvolvimento e o fortalecimento das redes de suporte social.

Palavras-chave: mídia, suicídio, idosos, riscos, suporte social.

As recomendações contidas no manual Comportamento suicida: conhecer para prevenir, dirigidas a profissionais de imprensa (Botega, 2009) sobre como abordar o suicídio são uma espécie de livro de receitas sobre notícias ou reportagens envolvendo o suicídio. Destacamos, entre elas, as seguintes:

a) A percepção de que a imprensa ficcional e não ficcional pode influenciar o suicídio é antiga. Goethe veio a público se defender, pois, aparentemente, uma centena de jovens cometera suicídio após a publicação de seu livro "Os sofrimentos do jovem Werther", em 1774. Alguns estavam vestidos ao estilo da personagem principal do livro, ou adotaram o mesmo método de suicídio, ou o livro foi encontrado no local da morte. Nesse romance, o protagonista se apaixona por uma mulher que não está ao seu alcance, e decide tirar a própria vida. $\mathrm{O}$ fenômeno originou o termo "Efeito Werther", usado na literatura médica para designar a imitação de suicídios.

b) Quando o suicídio for notícia (e esse critério varia entre os órgãos de imprensa), sugere-se reportagem discreta, cuidadosa com parentes e amigos enlutados, sem detalhismo exagerado do método suicida, notadamente quando o falecido era celebridade, ou pessoa muito estimada localmente. Acredita-se que carregar a reportagem de tensão, por meio de descrições e imagens de amigos e de familiares impactados, acabe por encorajar algumas pessoas mais vulneráveis a tomar o suicídio

* Autor correspondente: beltrina@pucsp.br como forma de chamar a atenção ou de retaliação contra outros.

c) Também não é recomendável abordar o suicídio unilateralmente como algo "normal", "compreensível", um ato de "livre-arbítrio" (basta observar o alto índice de transtornos mentais entre os falecidos). Ao invés disso, quando pertinente, seria melhor relatar uma história de sofrimento e investigar a possível contribuição de um transtorno mental no desenlace fatal. Lembrar, nesse ponto, que pessoas poderão ser ajudadas pela reportagem, caso obtenham uma descrição dos sintomas de uma doença mental ligada ao suicídio e uma relação de lugares onde poderão encontrar tratamento.

d) É bom esclarecer que, embora um transtorno mental seja um fator de risco relevante para o suicídio, isso não significa que o inverso seja verdadeiro, ou seja, que a maioria dos doentes (em especial os que têm depressão) se mate. Isso visa a evitar pânico desnecessário em pessoas acometidas por transtornos mentais (Botega, 2009, pp. 20-21).

O manual, publicado pela Associação Brasileira de Psiquiatria, reconhece no item "Prevenção de Suicídio no Brasil" que até recentemente o suicídio no país não era visto como um problema de saúde pública, mas a "necessidade de se discutir a violência, de modo geral, trouxe à tona o problema do suicídio" (Botega, 2009, p. 19). O documento relata que somente no final de 2005 o Ministério da Saúde criou um grupo de trabalho com a finalidade de elaborar um Plano Nacional de Prevenção do Suicídio, com representantes do governo, de entidades da sociedade civil 
e de universidades. No ano seguinte foi publicada uma portaria com as diretrizes que orientavam o Plano. Entre os principais objetivos a serem alcançados em relação à mídia, destaca-se informar e sensibilizar a sociedade de que o suicídio é um problema de saúde pública que pode ser prevenido.

A Organização Mundial da Saúde (OMS) reconhece que a mídia ocupa papel relevante na sociedade. Ela orienta atitudes, crenças, comportamentos e práticas políticas, econômicas e sociais, tendo "papel ativo na prevenção do suicídio". Não noticiar o suicídio é norma seguida pela maioria das empresas de comunicação do país, acolhendo a posição de não enfatizá-lo. O seu papel quanto à prevenção, no entanto, ainda não foi mensurado.

Tudo começou em 1774, quando, após a publicação do romance epistolar Os sofrimentos do jovem Werther, de Johann Wolfgang von Goethe, na Alemanha, sobreveio um surto de centenas de suicídios de jovens leitores por amores não correspondidos, que deixavam cartas-testamento. $\mathrm{Na}$ época, chegou-se à conclusão de que o livro intensificara tendências suicidas de jovens que deixavam ao lado do corpo um exemplar do livro. Em consequência, vários países proibiram a publicação da obra. Na época se atribuiu ao romance o efeito desencadeador, como um gatilho, para pessoas vulneráveis à ideia do suicídio. ${ }^{2}$

\section{A publicação de um suicídio na mídia será gatilho para outro suicídio?}

A pergunta foi feita por um estudioso da melancolia, George Howe Colt (2006), ao observar que em diversos lugares (Dallas, Beverly Hills, Ohio) dos Estados Unidos aconteceram no mesmo período vários suicídios, como se um desencadeasse outros tantos. O sociólogo americano David Phillips, citado por Colt (2006), ao estudar suicídio por imitação, encontrou aumento de $12 \%$ nos casos dos EUA em agosto de 1962, época do suicídio altamente publicizado da atriz Marilyn Monroe; foram 197 suicídios a mais do que seria esperado em um mês normal.

Apesar de Durkheim (1982) considerar restrito o número de casos nos quais a imitação acontece, a evolução dos meios de comunicação social levou David Phillips a denominar o "efeito Werther", em outras palavras, de efeito-imitação. A palavra suicídio passou a ser considerada "maldita" na sociedade, e consequentemente na mídia ou, "aquela-que-não-deve-ser-nomeada", analogia ao personagem do mal, Lord Voldemort, na série juvenil de livros e filmes Harry Potter. ${ }^{3}$

Desde então, o debate sobre tal influência se estabeleceu. Até hoje, a palavra suicídio é tratada como algo

2 Compartilhamos a definição de Marandola Jr. e Hogan (2006) sobre vulnerabilidade, conceito que aparece com frequência nas ciências sociais, substituindo os outrora conceitos de exclusão/inclusão, marginalidade, apartheid, periferização, segregação e dependência.

3 Harry Potter é uma série de aventuras fantásticas escrita pela britânica J. K. Rowling, constituída por sete livros, que ganhou grande popularidade e sucesso comercial em todo o mundo. "contagioso", sendo a mídia e a alta exposição os principais vírus dessa epidemia. O suicídio passou a ser tema não noticiável, e a mídia evita falar sobre ele - mas não é só a mídia. A população de modo geral, famílias, escolas e grupos sociais diversos preferem não tocar no assunto. $\mathrm{O}$ suicídio se tornou um ato tabu.

Steven Stack, um dos principais criminólogos contemporâneos, professor da Universidade Estadual de Wayne (EUA), critica os estudos sobre suicídios imitativos por deixarem de fora grande parte da população que não se deixou influenciar pela notícia divulgada. Oferece, por sua vez, outra pergunta: o que diferencia os "influenciáveis" dos demais? Segundo Stack, aqueles que apresentam predisposição ao suicídio ou comportamentos parecidos aos do suicida são de maior risco ao suicídio.

Estudo conduzido por Stack (2003) ressalta o risco de suicídio entre os idosos, enfatizando que dificuldades econômicas, solidão e doenças (físicas e mentais) tornariam os idosos um público com mais alto risco. Ele verificou que nos meses nos quais um ou mais suicídios foram amplamente divulgados, o número de suicídios de idosos aumentou, e que quando o suicídio era de pessoas idosas o efeito era ainda maior.

Essas e outras razões levaram à criação de um código de ética na mídia a respeito da publicação de notícias sobre suicídios, descritos nos manuais de redação ${ }^{4} \mathrm{e}$ em orientações, como a citada no início desta reflexão. A palavra "suicídio" deve ser evitada em chamadas e manchetes, incluindo-a apenas no corpo do texto, devendo ser evitada a colocação da matéria em primeira página e chamadas dramáticas, ou ênfase no impacto da morte sobre as pessoas próximas. Entre outras recomendações, o manual Comportamento suicida orienta os profissionais da mídia a não fornecer detalhes sobre o método letal, fotos, não usar termos valorativos e omitir o local onde o ato foi realizado, a fim de não criar "suicidiódromos". Além de sugerir que o profissional aproveite a oportunidade para conscientizar a população sobre a prevenção.

\section{Em pauta: um "fim digno" ante uma vida indigna}

Apesar de todas as recomendações, os oito recortes selecionados aleatoriamente de suicídios envolvendo sete pessoas idosas - cinco homens e duas mulheres - publicados na mídia de abril de 2010 a abril de 2013 não as seguiram. Pelo contrário, a palavra suicídio aparece na maior parte nos títulos das notícias e em todos os textos. Grifamo-nas em todos os recortes, demonstrando que, ao que tudo indica, o suicídio afasta-se do campo privado para ocupar e compor o espaço público. Afinal, se é um problema de saúde pública, deve assim ser enfrentado desde seu anúncio.

4 No Manual de Redação e Estilo do Estado não consta o verbete suicídio, que se encontra incluído apenas na definição de mortes. 
Nessa perspectiva, centramos esta reflexão em bilhetes deixados publicamente, em mensagens anunciadas e no próprio gesto extremo de comunicação em espaços públicos, com a finalidade de compreender o "recado" que os idosos suicidas nos transmitem.

No dia 5 de abril de 2012, em meio à crise europeia, foi publicada no Uol Notícias a seguinte matéria: "Suicídio de aposentado gera onda de protestos violentos na Grécia":

O suicídio de um aposentado em praça pública gerou uma nova onda de protestos nas duas maiores cidades do país, Atenas e Tessalônica. O homem, de 77 anos, suicidou-se com um tiro na cabeça na manhã da última quarta-feira, na Praça Sintagma, em frente ao Parlamento de Atenas, e deixou uma nota na qual afirma que sua pensão não dava para viver, depois dos muitos cortes que sofreu, e acusa o governo de traição.

A notícia narrava ainda que havia sido encontrada uma nota com o suicida (farmacêutico cujo nome não foi divulgado), que dizia:

O governo de ocupação aniquilou literalmente a minha capacidade de sobrevivência, baseada numa pensão que paguei durante 35 anos. Não encontro outra solução para um fim digno, antes de começar a procurar no lixo com que me alimentar.

Esse foi mais um entre tantos outros ocorridos na Grécia desde que o governo passou a executar uma série de medidas de austeridade, com o objetivo de reduzir o déficit público e o endividamento do Estado e garantir ajuda externa da União Europeia e do FMI. As aposentadorias foram fortemente afetadas pelos cortes e, consequentemente, as taxas de suicídio subiram no país.

O mesmo ocorreu na Itália, outro país bastante afetado pela crise econômica, como atesta a notícia "Suicídio de três idosos por causa de dívida choca a Itália" $(R 7$ Notícias, 05/04/2013), ressaltando as consequências do desemprego e da crise econômica que abateram a Europa, especialmente Grécia, Portugal e Itália, em 2008:

Romeo Dionisi, de 62 anos, e Anna Maria Sopranzi, de 68 , se enforcaram num depósito do qual eram donos, em Civitanova Marche, na costa do Adriático, segundo a polícia.

Após saber da morte da sua irmã, o irmão de Anna Maria, Giuseppe Sopranzi, de 72 anos, se atirou no mar e se afogou. As autoridades posteriormente resgataram seu corpo.

A imprensa relatou que o casal estava profundamente endividado e sobrevivia com uma pequena pensão recebida por Anna. Dionisi, pedreiro autônomo, não tinha direito a pensão e não estava encontrando trabalho.

Eles deixaram um bilhete no carro de um amigo, pedindo perdão pelo gesto extremo. Esses suicídios indicam como é devastador o impacto psicológico que a emergência econômica provoca na vida de homens e mulheres, o que frequentemente passa despercebido nas estatísticas cotidianas. Na ocasião, a mídia alternativa chegou a divulgar, em matéria assinada pelo jornalista e escritor Barbosa Filho (2012) "Europa: a face desumana da crise", que "economistas não atentam muito aos efeitos sociais e individuais de uma política recessiva levada ao extremo", destacando:

Na Grécia falida já se sabe que os suicídios aumentaram 17\% de 2007 para 2009, e dados ainda não oficiais acrescentam uma subida de $25 \%$ em 2010. Mas em Portugal não há nenhum estudo econométrico sobre o aumento da taxa de suicídios em relação a cada ponto percentual de retração do PIB. Há apenas uma informação da base de dados Pordata, registrando que 1098 pessoas suicidaram-se em 2010, ou 84 a mais do que no ano anterior, mas sem avaliação de quantas dessas mortes podem ser relacionadas aos problemas econômicos agravados.

O suicídio como forma de solução dos problemas é praticado na sociedade coreana desde 1997, ano em que se deu a crise financeira asiática, que gerou crescente instabilidade empregatícia e alta taxa de suicídios, especialmente entre idosos. O suicídio é a quarta causa de morte atualmente na Coreia do Sul, e com relativa frequência há notícias como esta: "Onda de suicídios comove Coreia do Sul” (Maisonnave, 2010), assinalando que é o país asiático com maior índice de suicídio entre os 32 países mais ricos do mundo. A matéria enfatiza:

Na Coreia do Sul ocorrem 40 suicídios diários, de pessoas comuns, do meio artístico, políticos, membros das mais variadas classes sociais. As estatísticas para pessoas com mais de 80 anos é de 100 por 100 mil habitantes. Os idosos são o grupo mais afetado.

A Coreia do Sul é uma sociedade em rápido processo de envelhecimento, de acordo com o psiquiatra $\mathrm{Ha}$ Giu-sup, da Universidade Nacional de Seul e presidente da Associação Sul-Coreana para a Prevenção do Suicídio. Segundo ele, os idosos não se prepararam para viver tanto tempo porque, quando jovens, poucas pessoas viviam mais de 60 anos. Mas a "solidão da vida na área rural, a pobreza e a doença acabam por vezes levando os idosos a cometer suicídio" (Maisonnave, 2010).

Em tempos de maior crise, o que já é pouco e sofrível, como a poupança ou o salário do aposentado, reduz-se a migalhas. Isto é motivo para se cometer um ato de comunicação tão extremo e ao mesmo tempo tão irremediável sob todos os aspectos?

Talvez a primeira resposta, mais simples e cômoda, seja atribuir algo ao "outro". Aquele que priva, destrói, trai, rouba e ainda transforma o morto em vítima do sistema. O suicida imputa culpa a esse "outro", por meio de 
pequenas notas ou cartas póstumas, sem contornos, vilão sem perdão. Um ato desesperado? Um ato digno/covarde? Depressão não tratada? Doença mental? Repulsa à vida? Ou luta por uma morte digna?

"Cresce suicídio entre idosos na Coreia do Sul" (Sang-Hun, 2013) traz à tona outra questão, igualmente relacionada à crise financeira, que é a ruptura do tradicional contrato social da época de Confúcio, ${ }^{5}$ no qual os mais velhos podem contar com o respeito e o apoio dos filhos e netos:

Quando uma mulher de 78 anos se matou em agosto bebendo pesticida na frente de uma prefeitura, sua história mostrou um problema que até recentemente fora abafado: na Coreia do Sul, onde o respeito pelos mais velhos é um dos esteios da ordem social, idosos estão cometendo suicídio em ritmo alarmante.

Viúva, a mulher vivia sozinha e recebia uma pensão do Estado. Mas o governo local soube que seu cunhado, até então desempregado, havia encontrado um trabalho. Retirou-lhe a pensão, citando regulamentos que negam benefícios a pessoas cujos filhos ou parentes adultos são considerados capazes de sustentá-las. De nada adiantou a mulher apelar, afirmando que não podia mais pagar o aluguel. Ela deixou um bilhete: "Como vocês podem fazer isso comigo? A lei deve servir às pessoas, mas não me protegeu".

A notícia ressalta a transição da sociedade coreana agrícola para a industrial, o que levou a geração mais jovem para as cidades ou exterior, dissolvendo a base de apoio familiar de forma mais rápida do que o sistema nacional de aposentadorias, que começou em 1988. Em consequência, diversas pessoas, hoje na faixa de 80 anos, não tiveram como aderir. Até então, eles tinham somente os filhos para o futuro, aí incluídos os tratamentos de saúde, apoio financeiro e uma vida confortável na velhice.

Além da população envelhecer mais rapidamente do que a de outros países desenvolvidos, na Coreia do Sul, "os velhos sentem-se traídos ou pensam que são um peso para seus filhos, principalmente os que têm doenças crônicas cujas contas médicas os filhos lutam para pagar", destaca Park Jiyoung, professora de Assistência Social na Universidade Sangji. Segundo ela, "sua crença na família como uma entidade com um destino comum os leva a afastar-se dela, removendo o peso" (Sang-Hun, 2013).

As narrativas indicam que ter filhos hoje não resguarda os velhos coreanos da solidão. Filhos não representam garantia de companhia, menos ainda de conversa e

5 Os princípios de Confúcio se baseavam nas tradições e crenças chinesas comuns. Favorecia uma lealdade familiar forte, veneração dos ancestrais, respeito aos idosos e às crianças, e a família como a base para um governo ideal. afeto, e nem podem ser obrigados a algo que não querem, não sentem ou não podem.

\section{Em pauta: "fim digno" para os efeitos do prolongamento da vida}

As notícias "Homem comete suicídio por temer velhice" (45Graus, 28/01/2013) e "Confirmado suicídio de Walmor Chagas, polícia agora investiga as causas" (Veja, 21/03/2013), publicadas em janeiro de 2013, abordam não apenas o medo dos efeitos do processo do envelhecimento e de uma sobrevivência indefinida, mas também vislumbram cenários nos quais está em jogo o prolongamento da morbidade, e não um envelhecimento produtivo ou a aceitação voluntária da finitude.

A primeira notícia afirma:

O senhor Francisco Ferreira, de 85 anos, foi encontrado morto na tarde deste domingo (27) no Povoado Novo Nilo, zona rural de União. Francisco teria tirado a própria vida com um tiro de espingarda no pescoço. A bala teria atravessado também a cabeça. Segundo informações de amigos e familiares, Francisco sempre falava que não queria ficar idoso ao ponto de depender totalmente das pessoas, por isso teria cometido o ato. $\mathrm{O}$ fato aconteceu por volta das 13:30h de domingo, no quintal da residência do mesmo, e abalou o Povoado Novo Nilo durante esta segunda-feira (28). A comunidade local está de luto. Francisco era aposentado e seu sepultamento ocorreu no turno da tarde. Ele era tio do médico unionense Dr. Cláudio Ferreira. (45Graus)

A segunda trata da morte do ator Walmor Chagas, amplamente publicizada. Em ambas, a palavra suicídio aparece no título. No entanto, inicialmente a mídia "escondeu" o suicídio do ator. Distintos jornais afirmavam que ele havia morrido, e "apesar de ter sido encontrado sentado na cozinha com uma arma no colo e um tiro na cabeça, pelo caseiro da fazenda às cinco horas da tarde, a polícia ainda estava investigando a causa da morte e que havia uma chance de ter sido furto":

A versão de que o ator Walmor Chagas cometeu suicídio é dada como certa pela polícia, após emissão de laudo provisório criminal nesta segundafeira, em Guaratinguetá, no interior de São Paulo. Segundo o delegado Antonio Luiz Marcelino, da $2^{\text {a }}$ DP de Guaratinguetá, os próximos passos da investigação vão buscar os motivos que levaram o ator a tirar a própria vida. Vizinhos e familiares serão ouvidos nas próximas semanas. $\mathrm{O}$ inquérito tem prazo máximo de 30 dias para ser concluído e o período pode ser estendido se for necessário.

$\mathrm{O}$ ator foi encontrado morto na última sexta-feira, em seu sítio, em Guaratinguetá. Apenas o caseiro 
José Arteiro de Almeida estava no local, e disse à polícia ter ouvido um disparo antes de encontrar o patrão sem vida. A perícia criminal encontrou vestígios de pólvora na mão direita do ator. Não havia indícios da substância no corpo do caseiro.

A principal hipótese é que o suicídio tenha sido motivado pelos problemas de saúde que limitaram seus movimentos nos últimos anos. De acordo com o delegado Marcelino, o ator também sofria de solidão. A advogada da família, Maria Dalva Coppola, confirmou as dificuldades de locomoção e visão enfrentadas por Walmor. (Veja)

"Walmor Chagas escolheu a hora de sua morte, diz amigo do ator ao falar sobre suposto suicídio" (Rodrigues, 2013), é o título de outra notícia, que narra que ele não queria ser um peso para ninguém. O empresário e amigo de Walmor, Antônio Carlos Cardoso, afirmou:

$\mathrm{O}$ ator tirou a própria vida porque estava muito doente e não queria dar trabalho para amigos e parentes. Acredito que seu suicídio foi resultado da sua teimosia, não queria ser um peso para ninguém. Ele, na verdade, quis escolher a hora de sua própria morte. (Rodrigues, 2013)

Em outra matéria ("Limitações da velhice enclausuraram Walmor", diz advogada), Maria Dalva Coppola afirma que ele não conseguia executar movimentos simples sem ajuda, como curvar-se para entrar no carro (Costa, 2013). Ele queria fazer tudo sozinho. Segundo ela, não havia diagnóstico de depressão, e a família não sabia de remédios antidepressivos que ele estivesse tomando.

Vale lembrar, no entanto, que a última peça de teatro estrelada e escrita por Walmor debatia o suicídio ("Um homem indignado", 2004), monólogo em que ele fazia o papel de um ator veterano que se debruça sobre enfermidades sociais e, desesperançoso com a velhice, põe fim à própria vida. Mera coincidência?

Diferentemente das demais notícias, o suicídio de Walmor Chagas suscitou várias outras, entre elas a de Noronha (2013), e em todas aparecia o alerta para a depressão na velhice:

O suicídio do ator, diretor e produtor Walmor Chagas, no dia 18 de janeiro, trouxe à tona um assunto espinhoso, mas de suma importância: a depressão na terceira idade. Aos 82 anos, Walmor vivia praticamente isolado em um sítio no interior de São Paulo. Enxergava mal, tinha dificuldades para andar, se alimentava pouco e contava frequentemente com a ajuda de empregados para executar tarefas cotidianas. Um de seus amigos disse à imprensa que o artista teria comentado que desejaria partir, caso se tornasse uma pessoa dependente.
Somente a partir do suicídio do ator, amplamente divulgado em todos os veículos de comunicação, a mídia começou a contextualizar e a ouvir especialistas na área, centrando-se na solidão de pessoas idosas (Noronha, 2013). Provavelmente a imprensa refletia o tabu social de não comentar os casos de suicídio, de não aprofundar a análise do suicídio. Mas o suicídio no Brasil é um problema, como relatam os especialistas ouvidos pela reportagem:

A perda de parceiros e amigos de toda uma vida pode contribuir para o surgimento da depressão. Quando morre alguém querido, morre também uma parte sua. Para um idoso isso é ainda mais grave, porque ele sabe que foi embora um pedaço de sua vida que nunca mais vai poder viver de novo. (Denise Diniz, Unifesp)

As limitações típicas da velhice são o principal detonador dos casos de depressão entre idosos. O sistema imunológico, a visão e a capacidade motora e de locomoção ficam comprometidos. Em alguns casos, a pessoa requer auxílio até para fazer a própria higiene. É uma fase de difícil aceitação, e há quem jamais a aceite. (Denise Diniz, Unifesp)

E mesmo em circunstâncias em que as condições monetárias são boas, há casos em que a depressão e as limitações os atrapalham, impedindo-os de fazer suas escolhas e tornando-os apáticos demais. (Denise Diniz, Unifesp)

Hoje em dia, a maioria das famílias não tem tempo ou estrutura para cuidar dos idosos. Todos têm de trabalhar e os deixam sós. A solidão, a falta de dinheiro e a dependência entristecem. (Sônia Fuentes, mestre em Gerontologia, PUC-SP)

Em "Walmor Chagas e o suicídio entre idosos", a colunista Cláudia Collucci, da Folha de S. Paulo, registra que a morte do ator revela uma triste realidade no país: a alta taxa de idosos que dão fim à própria vida, elencando dados: $51 \%$ dos suicídios de idosos ocorrem em casa; dos 50 municípios brasileiros com os índices mais elevados de mortes, $90 \%$ estão no Sul; $54 \%$ dos municípios brasileiros já registraram casos de suicídios de pessoas acima de 60 anos; $67 \%$ estavam em atendimento em serviços de atenção primária nos últimos 30 dias de vida e até meia semana antes de cometer o ato; famílias, parentes e amigos muitas vezes não levam a sério as intenções de suicídio, mesmo quando explicitadas verbalmente; e no caso dos idosos, as intenções podem ser mais rapidamente colocadas em prática do que entre os mais jovens.

Perda de parentes referenciais, sobretudo do cônjuge; solidão; existência de enfermidades degenerativas e dolorosas; sensação de estar dando muito trabalho à família; ser um peso morto e abandono são os principais 
motivos que levam as pessoas idosas a se suicidarem. (Collucci, 2013)

A autora ressalta ainda, na matéria, que entre os principais fatores de risco para ambos os sexos estão a depressão e transtornos mentais. A solidão e o isolamento social são os principais fatores associados nos casos dos homens, destacando as ações de prevenção. Em relação às mulheres, por terem redes de proteção mais fortes e se engajarem mais facilmente do que os homens em atividades domésticas e comunitárias, elas se suicidam menos. Assinala ainda a importância da participação social até o final da vida (Collucci, 2013).

Publicada em fevereiro de 2013, a notícia "Quando os bravos se suicidam", escrita pelo jornalista Lúcio Flávio Pinto, narra o contexto em que ocorreu o suicídio do jornalista José Eduardo de Faro Freire, trazendo à luz a fragilidade de um corpo e de uma mente lúcida:

Uma semana depois de ter escrito sobre o suicídio do ator Walmor Chagas, na edição $n^{0} 529$ do Jornal Pessoal, recebi o impacto direto de um fato que podia ser associado ao anterior. Meu amigo paulista José Eduardo de Faro Freire voltou de uma consulta médica e se matou com um tiro de revólver no peito. Foi sua reação à má notícia de que tinha um tumor incurável no cérebro. Era o golpe mais duro numa sucessão de infortúnios de saúde. Aos 71 anos, Zé Eduardo pressentiu um destino cruel, que sempre rejeitara: tornar-se inválido nos momentos finais da sua vida.

O corpo já vinha dando sinais de esgotamento, fazendo-o recorrer a uma cadeira de rodas. $\mathrm{O}$ câncer tornava inútil o combate que ele travava por sua vida. Não valia mais a pena viver. Ela iria se tornar vegetativa, dependente de terceiros. Descaracterizaria completamente sua vítima.

Todos nós, seus amigos, tínhamos de José Eduardo de Faro Freire a imagem de um ser vital, cheio de energias, vivendo intensamente cada dia, entusiasmado pelo que fazia e inteiramente solidário ao que os outros faziam. Um centauro sob a armadura de um cético, iconoclasta, quase um anarquista. Um autêntico personagem, aquele tipo ideal de que nos fala a sociologia quando quer tratar de pessoas que impõem sua marca em todos os lugares pelos quais passaram. (Pinto, 2013)

Essas notícias alertam para o desgaste biológico natural das funções do corpo, que pode trazer limitações e, algumas vezes, dependência, especialmente na presença de doenças crônicas e incapacitantes, constituindo situações de vulnerabilidade e risco para o suicídio.

\section{Em pauta: as situações de risco ao suicídio por idosos}

As pessoas idosas passam por uma série de mudanças em sua vida que, especialmente nas sociedades ocidentais como a nossa, as predisporiam ao suicídio. Entendemos aqui por situação de risco o fenômeno que inclui todas as instâncias que têm contato com a pessoa idosa, de ordens biológica, fisiológica, afetiva, social, econômica e de organização do cotidiano. A aposentadoria, que em geral se faz acompanhar de redução dos rendimentos, restrição do convívio social e perda de status, compõe esse fenômeno. É até mesmo devastador o impacto psicológico que a emergência econômica provoca na vida de homens e mulheres, o que frequentemente não se percebe por trás das estatísticas do cotidiano, e que vem à tona quando há notícias como "Suicídio de aposentado gera onda de protestos violentos na Grécia" e "Cresce suicídio entre idosos na Coreia do Sul", entre outras.

As situações de risco gerariam sentimentos de inutilidade, de menos valia, de humilhação ou castigo, de solidão, um peso para a família. Compõem também situações de risco, o medo da dependência e de vir a dar trabalho aos outros (Frank \& Rodrigues, 2006); e o medo do prolongamento da vida sem dignidade (Minayo \& Cavalcante, 2010), como o caso das notícias "Homem comete suicídio por temer velhice", "Confirmado suicídio de Walmor Chagas, Polícia agora investiga as causas" e "Quando os bravos se suicidam".

Fazem parte ainda das situações de risco a morte do companheiro e de outros pares, como amigos e irmãos, o que acarreta tristeza, levando à perda de referência, de sentido de vida e isolamento social, como aconteceu com o irmão de Anna Maria Sopranzi, na notícia "Suicídio de três idosos por causa de dívida choca a Itália". O preconceito, o desrespeito e a discriminação social, advindos não apenas dos indivíduos, mas do poder público e das instituições, constituem situações de risco ao suicídio.

A situação de risco ao suicídio por idosos envolve a presença de depressão, em geral associada às perdas acumuladas ao longo da vida; ausência ou carência de suporte social, isolamento e solidão; e doenças acompanhadas de dores incontroláveis e prolongadas (Baptista, 2004; Frank \& Rodrigues, 2006; Minayo \& Cavalcante, 2010; Vieira, 2004).

São fatores de risco os transtornos de ansiedade e o abuso de álcool e outras drogas (Baptista, 2004; Frank \& Rodrigues, 2006). Nos idosos mais jovens, o abuso de álcool é fator importante quando associado a estressor psicossocial (Frank \& Rodrigues, 2006). A morte de pessoas queridas também é um fator, principalmente do cônjuge (Minayo \& Cavalcante, 2010; Frank \& Rodrigues, 2006), em especial entre os homens, sendo maior o risco no primeiro ano de viuvez, histórico de uma tentativa prévia de suicídio e histórico familiar (Frank \& Rodrigues, 2006).

Além dessas situações, Baptista (2004) ressaltou, com base em ampla revisão de literatura acerca das situações de risco associados ao suicídio em adolescentes e adultos, fatores psicossociais. Acreditamos que estariam presentes na ideação ou no comportamento suicida entre idosos: a percepção negativa ou catastrófica sobre os fatores estressantes; traços específicos de comportamento, como pouca tolerância a frustrações, 
agressividade e impulsividade; baixa autoestima; e pouco senso de controle das situações, ou seja, acreditar que têm pouca chance de mudar determinada situação. Qual a chance de se mudar uma situação que envolve um tumor incurável no cérebro de um homem de 71 anos de idade, que vinha travando uma guerra contra um câncer que a cada dia o deixava mais inútil, como na notícia "Quando os bravos se suicidam"? Lúcido, José Eduardo percebia sua sobrevivência transformada pelo tempo cronológico, irreconhecível.

Os dados, em termos de prevalência e fatores associados às situações de risco de suicídio de idosos, por si mesmos não apresentam a complexidade que envolve a angústia de uma existência cada vez mais prolongada e muitas vezes indigna. Assim são os dados da Organização Mundial da Saúde: o suicídio vitima cerca de um milhão de pessoas no mundo por ano, tornando-o problema de saúde pública mundial (Baptista, 2004; Minayo \& Cavalcante, 2010). No Brasil, a taxa é mais baixa do que na maioria dos países (Minayo \& Cavalcante, 2010).

A taxa de suicídio é maior entre idosos, comparada aos mais jovens, especialmente para os homens (Frank \& Rodrigues, 2006; Minayo \& Cavalcante, 2010). O suicídio representa a décima causa de morte no grupo de mais de 65 anos, fato que se amplifica entre idosos de 80 a 84 anos (Vieira, 2004).

Em geral, os idosos são bem-sucedidos logo na primeira tentativa. Além de planejarem mais, utilizam métodos mais letais para cometê-lo, como armas de fogo ou precipitação no vazio (Frank \& Rodrigues, 2006; Minayo \& Cavalcante, 2010; Vieira, 2004). Nas notícias analisadas, três idosos se suicidaram com arma de fogo, dois com enforcamento, um envenenamento e um por afogamento. Entre idosos é incomum histórico de tentativas prévias. Alguns idosos adotam comportamentos autodestrutivos: não se alimentam, não aderem ao tratamento e se autonegligenciam (Frank \& Rodrigues, 2006; Minayo \& Cavalcante, 2010; Vieira, 2004), atitudes muito comuns entre institucionalizados ou àqueles que consideram o suicídio um pecado (Frank \& Rodrigues, 2006).

Os idosos dão indícios comportamentais e verbais, diretos e indiretos, de sua intenção suicida; porém, muitas vezes são ignorados (Frank \& Rodrigues, 2006; Minayo \& Cavalcante, 2010; Vieira, 2004). Alguns indícios comuns são: separar documentos em pastas como se quisessem resolver tudo antes de morrer; mudanças no testamento; declarações de que a família estaria melhor sem ele; afirmar que está cansado de viver (Vieira, 2004); descuido com a medicação; desinteresse em se cuidar e pelas coisas da vida; e busca súbita por alguma religião ou igreja (Minayo \& Cavalcante, 2010).

Isso aconteceu na notícia "Homem comete suicídio por temer velhice", em que amigos e familiares informaram que "Francisco sempre falava que não queria ficar idoso a ponto de depender totalmente das pessoas". $\mathrm{Ou}$, no caso do suicídio do ator Walmor Chagas: havia avisado a amigos que "não queria ser um peso para ninguém". É possível levar em consideração seu aviso, já em 2004, quando debateu o suicídio na peça "Um homem indignado".

Até que ponto a vida vale a pena para casos como o de Francisco, Walmor e José Eduardo? Em breve pode ser que aconteceça a outros. Até que ponto temos o direito de intervir na liberdade e vontade do outro de terminar a própria vida? Até que ponto temos o direito de fazer investidas para condenar o outro a permanecer em uma situação que ele não suporta mais? São questionamentos factíveis do ponto de vista das liberdades individuais e do existencialismo, considerando uma vida cada vez mais longeva e, na maioria das vezes, não digna. A sociedade deve repensar os avanços da medicina que apenas acrescentam anos à vida.

Do ponto de vista do sofrimento psíquico, considerando-se que o suicídio é um gesto extremo de comunicação - quando a pessoa não vê saída para a sua situação -, existem medidas preventivas. A literatura coloca o acompanhamento médico e psicológico (Baptista, 2004; Frank \& Rodrigues, 2006; Vieira, 2004) com retornos de curto prazo e monitoramento. Além da medicação para produzir a secreção de neurotransmissores benéficos ao equilíbrio emocional e bem-estar, é imprescindível a intervenção psicológica visando modificar a avaliação que a pessoa faz de sua situação, por meio da reestruturação cognitiva e via mudanças em seu ambiente físico e social, de tal forma que lhe proporcionam melhor qualidade de vida e sentimentos mais positivos, diminuindo a probabilidade de tentar o suicídio.

Há ainda campanhas e até ações menores, isoladas, com efeitos benéficos por estimular os que se sentem só, e não sabem onde e como obter auxílio, a agir e se movimentar. No caso de pessoas com depressão, contraditoriamente, quando estão saindo do quadro depressivo, especialmente quando há melhora dos sintomas somáticos antes da remissão da ideação suicida, há maior possibilidade de cometerem suicídio (Frank \& Rodrigues, 2006; Vieira, 2004). Medidas ambientais são importantes, como verificar se entre os pertences do idoso existem objetos cortantes ou perfurantes, cordas, armas ou quaisquer outros que representam risco à integridade física; colocar grades de proteção nas janelas e demais mudanças que trazem maior segurança (Vieira, 2004).

Ao mesmo tempo, o suicídio tem que "sair do armário" e ir para as rodas de conversas em centros de convivência de idosos, Unidades Básicas de Saúde e Faculdades Abertas da Terceira Idade. Deve ser mostrado como um problema que ficou durante muito tempo debaixo do tapete. Como assinala o documentário Suicídio no Brasil (Fiocruz, 2012), deve-se falar sobre suicídio "com sensibilidade, com o auxílio de várias fontes de conhecimento, de várias visões sobre esse fenômeno tão complexo", a fim de aumentar as chances de reflexão e ampliar a possibilidade de encontrar saídas para a angústia do homem cada vez mais longevo. 


\section{Papel da rede de suporte social}

O Estudo Multicêntrico de Intervenção no Comportamento Suicida (SUPRE-MISS), desenvolvido pela Organização Mundial da Saúde em dez países, incluindo o Brasil, baseou-se em ensaios terapêuticos com pessoas que tentaram o suicídio, revelando a importância do suporte social. Nessa estratégia, indivíduos atendidos em pronto-socorros por tentativa de suicídio foram divididos aleatoriamente em dois grupos: um grupo recebeu "tratamento usual" (geralmente alta do pronto-socorro sem encaminhamento a serviço de saúde mental); outro grupo recebeu uma "intervenção breve", que incluiu entrevista motivacional e telefonemas periódicos. Um total de 1867 casos de tentativas de suicídio foi avaliado e dividido aleatoriamente nos dois grupos. Ao final de 18 meses, a "intervenção breve" reduziu em dez vezes o número de suicídios em relação ao grupo que recebeu o "tratamento usual" (Fleischmann et al., citado por Botega, 2010).

Minayo e Cavalcante (2010) enfatizam a necessidade de desenvolver uma rede social de suporte na qual sejam contempladas todas as relações que as pessoas estabelecem durante a vida cotidiana. Nelas, acrescentamos, deverão fazer parte profissionais e funcionários, de instituições públicas ou privadas, que fornecem atenção, orientação e informação, até as relações entre os indivíduos na comunicação mediada por computador.

Finalizando, na perspectiva de envelhecimento atual, favorecemos a existência de uma rede mínima de suporte social e psicológico que atenda às angústias de nosso longeviver? Qual deverá ser o papel da mídia no fortalecimento das redes sociais? Ao invés de se criar manuais para evitar nomear a palavra que não deve ser dita, por que não criar cartilhas que orientem os profissionais da mídia a retratar e fortalecer as redes de suporte social que existem e estão dispersas?

Ressaltamos como elementos inalienáveis da existência humana moldada por considerações humanísticas e não econômicas, o fortalecimento das redes de suporte social a fim de lidarmos, sem negar nem suprimir, com a transitoriedade da vida, a doença e o longeviver.

\section{Elderly suicide and the media: What does the news say?}

Abstract: How is the media addressing elderly suicide? And what does the news about elderly suicide tell us? These were the questions which guided this reflection, addressing the news about elderly suicide published on Brazilian media from April 2010 to April 2013. We have noticed that the word "suicide" - that until recently "should not be mentioned" by the media - appears in most of the news, both in its headlines and inside the texts, showing that suicide, as a public health issue, moves from the private field to occupy and compose the public space. We found out that the main risk situations that lead seniors to commit an extreme communication gesture resulted from the effects of recessive economic politics, as well as life extension without dignity in view of the fear of dependence and causing trouble to other people. Such situations indicate the need of developing and strengthening social support networks.

Keywords: media, elderly, suicide, risks, social support.

\section{Suicide des personnes âgées et media : que disent les informations?}

Résumé: Comment les médias abordent-elles le suicide des personnes âgées? Que nous transmettent les informations sur le suicide des gens âgées? Telles étaient les questions clé de cette réflexion qui s'est penché sur les publications de suicide de personnes âgées dans les médias nationales entre avril 2010 et avril 2013. Nous notons que le mot "suicide" jusque récemment "le mot qui ne devait pas être cité" dans la presse, apparaît dans la plupart des informations, aussi bien dans les titres que dans les articles, ce qui démontre que le suicide comme problème de santé publique s'éloigne d'un champ privé pour occuper et composer un espace publique. Nous pouvons noter que les principales situations à risque qui conduisent les gents âgées à commettre un acte de communication extrême sont les effets d'une politique économique récessive, le prolongement de la vie sans dignité face à la crainte de la dépendance et la peur de donner du travail aux autres. Ces situations indiquent le besoin de développer et consolider les réseaux de soutien social.

Mots-clés: médias, suicide, personnes âgées, risques, soutien social.

\section{Suicidio de personas mayores e medios: ¿qué dicen las noticias?}

Resumen: ¿Cómo vienen abordando los medios el suicidio de personas mayores? Y ¿Qué es lo que las noticias sobre suicidio de personas mayores nos están diciendo? Estas han sido las preguntas guías de esta reflexión que se analizó 
las noticias de suicidios de personas mayores publicadas en los medios nacionales, entre abril de 2010 y abril de 2013. Observamos que la palabra "suicidio", que hasta hace poco tiempo era "aquella que no-debería ser nombrada" en la prensa, aparece en la mayoría de las noticias, tanto en sus titulares como en el interior de los textos, demostrando que el suicidio, como problema de salud pública, se aleja del campo privado para ocupar el campo del espacio público. Constatamos que entre las principales situaciones de riesgo que llevan a las personas mayores a cometer un gesto de comunicación extremo, están los efectos de una política económica recesiva, así como el prolongamiento de la vida sin dignidad frente al miedo de la dependencia y de llegar a darles trabajo a los demás. Situaciones que indican la necesidad de desarrollarse y fortalecer redes de soporte social.

Palabras clave: medios, suicidio, personas mayores, riesgos, soporte social.

\section{Referências}

Baptista, M. N. (2004). Suicídio e depressão: atualizações. Rio de Janeiro, RJ: Guanabara-Koogan.

Barbosa Filho, A. (2012). Europa: a face desumana da crise. Recuperado de http://outraspalavras.net/posts/europa-aface-desumana-da-crise/

Botega, N. J. (Org.). (2009). Comportamento suicida: conhecer para prevenir, dirigido para profissionais de imprensa. São Paulo, SP: Associação Brasileira de Psiquiatria.

Collucci, C. (2013). Walmor Chagas e o suicídio entre idosos. Recuperado de www1.folha.uol.com.br/colunas/ claudiacollucci/2013/01/1219075-walmor-chagas-e-osuicidio-entre-idosos.shtml

Colt, G. H. (2006). November of the soul-the enigma of the suicide. New York: Scribner.

Confirmado suicídio de Walmor Chagas. Polícia agora investiga as causas. (2013, 21 de janeiro). Veja. Recuperado de http:// veja.abril.com.br/noticia/celebridades/confirmado-suicidiode-walmor-chagas-policia-agora-investiga-as-causas

Costa, A. C. (2013). Limitações da velhice enclausuraram Walmor, diz advogada. Recuperado de http://veja.abril. com.br/noticia/celebridades/limitacoes-da-velhiceenclausuraram-walmor-diz-advogada

Durkheim, E. (1982). O suicídio: estudo sociológico. Rio de Janeiro, RJ: Zahar.

Frank, M. H., \& Rodrigues, N. L. (2006). Depressão, ansiedade, outros distúrbios afetivos e suicídio. In E. V. Freitas, L. Py, F. A. X. Cançado, J. Doll \& M. L. Gorzoni (Orgs.), Tratado de geriatria e gerontologia (2a ed., pp. 376-401). Rio de Janeiro, RJ: Guanabara-Koogan.

Fiocruz. (2012). Suicídio no Brasil [vídeo]. Recuperado de http://vimeo.com/36487179

Goethe, J. W. (2004). Os sofrimentos do jovem Werther. Porto Alegre, RS: L\&PM Pocket.

Homem comete suicídio por temer velhice. (2013, 29 de janeiro). 45 Graus. Recuperado de http://www.45graus. com.br/homem-comete-suic-dio-por-temervelhice,uniao, 102382.html

Maisonnave, F. (2010). Onda de suicídios comove sulcoreanos. Recuperado de http://wwwl.folha.uol.com. br/fsp/mundo/ft3008201006.htm

Marandola Jr., E., \& Hogan, D. (2006). As dimensões da vulnerabilidade. São Paulo em Perspectiva, 20(1), 3343. São Paulo: Fundação SEADE.
Minayo, M. C. S., \& Cavalcante, F. G. (2010). Suicídio entre pessoas idosas: revisão da literatura. Revista de Saúde Pública, 44(4), 750-757.

Noronha, H. (2013). Suicídio de Walmor Chagas serve de alerta para a depressão na velhice. Recuperado de http://mulher.uol.com.br/comportamento/noticias/ redacao/2013/01/24/suicidio-de-walmor-chagas-servede-alerta-para-a-depressao-na-velhice.htm

Pinto, L. F. (2013). Quando os bravos se suicidam. Recuperado de http://observatoriodaimprensa.com.br/ news/view/_ed734_quando_os_bravos_se_suicidam

Rodrigues, E. (2013). Walmor Chagas escolheu a hora de sua morte, diz amigo do ator ao falar sobre suposto suicídio. Recuperado de http://televisao.uol.com.br/ noticias/redacao/2013/01/19/walmor-chagas-escolheua-hora-de-sua-morte-diz-amigo-do-ator-ao-falar-sobresuposto-suicidio.htm

Sang-Hun, C. (2013). Cresce suicídio entre idosos na Coreia do Sul. Recuperado de http://wwwl.folha.uol.com.br/ fsp/newyorktimes/89640-cresce-suicidio-entre-idososna-coreia-do-sul.shtml

Stack, S. (2003). Media coverage as a risk factor in suicide. Journal of Epidemiology and Community Health, 57(4), 238-240. Recuperado de http://jech.bmj.com/ content/57/4/238.full.pdf

Suicídio de aposentado gera onda de protestos violentos na Grécia. (2012, 05 de abril). Uol Notícias. Recupersado de http://noticias.uol.com.br/ ultimas-noticias deutschewelle/2012/04/05/suicidio-deaposentado-gera-onda-de-protestos-violentos-na-grecia. htm

Suicídio de três idosos por causa de dívida choca a Itália. (2013, 05 de abril). R7 Notícias. Recuperado de http:// noticias.r7.com/internacional/suicidio-de-tres-idosospor-causa-de-divida-choca-a-italia-05042013

Vieira, E. B. (2004). Manual de gerontologia: um guia teórico-prático para profissionais, cuidadores e familiares. Rio de Janeiro, RJ: Revinter.

Recebido: 07/10/2013

Revisado: 14/11/2013

Aceito: 07/04/2014 